\title{
EUTOMIA
}

Revista de Literatura e Linguística

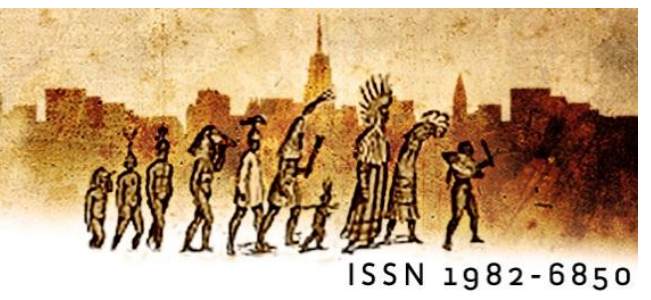

\section{Sombras do opus magnum: Samuel Beckett dirige a última gravação de Krapp}

Felipe Augusto de Souza Santosi (USP-FAPESP)

Resumo: O presente artigo tem como objetivo apresentar uma reflexão acerca do trabalho de Samuel Beckett como encenador de sua própria dramaturgia. Para tanto, abordaremos as encenações dirigidas por Beckett de A última gravação de Krapp, observando detalhes do trabalho de transposição realizado pelo dramaturgo-encenador de sua dramaturgia para o palco.

Palavras-chave: Samuel Beckett, A última gravação de Krapp, dramaturgia, encenação, teatro moderno.

Abstract: This article aims to present a reflection on the work of Samuel Beckett as the director of his own dramaturgy. For that, we will approach the stagings directed by Beckett of Krapp's Last Tape, observing details of the work of transposition realized by the playwright-director of his dramaturgy for the stage.

Key-words: Samuel Beckett, Krapp's Last Tape, dramaturgy, staging, modern theatre. 
Embora ainda pouco conhecida no Brasil, a trajetória de Samuel Beckett (1906-1989) no campo da encenação teatral foi longa e duradoura, resultando em algumas das mais importantes versões para o palco de peças como Esperando Godot, Fim de partida, A última gravação de Krapp, Dias felizes, Passos, entre outras. A cada processo de encenação, o dramaturgo-encenador preparava cadernos de direção meticulosos, contendo anotações detalhadas relativas a todos os elementos da composição da dramaturgia e propostas de modificações cênicas, resultando, na maioria das vezes, em uma "versão final" da peça, redimensionada de acordo com as exigências do processo de encenação e da adaptação de sua estética para o palco, contendo cortes e alterações que constituem verdadeiros ganhos em relação aos textos originais publicados.

Samuel Beckett se envolveu em diversas produções teatrais de A última gravação de Krapp, desde a estreia da peça em 1958, com o ator para quem havia escrito o texto no papel de Krapp, Patrick Magee, e sob direção de Donald McWhinnie, no Royal Court Theatre de Londres. Apesar de acompanhar os ensaios da peça [prática que estava iniciando naquela altura], Beckett evitou comentar e sugerir elementos para a montagem, devido à sua admiração pelo trabalho do ator que fora sua inspiração para conceber o personagem e também pelo respeito ao trabalho do diretor Donald McWhinnie. Anos depois, "quando McWhinnie dirigiu novamente Magee como Krapp para a BBC Television, em 25 de outubro de 1972, Beckett enviou anotações, mas novamente evitou impor sua visão à produção" (MCMILLAN; FEHSENFELD, 1988, p. 256, tradução nossa). A parceria com o ator que havia inspirado Beckett a compor a peça ainda renderia mais um fruto. Em 1975, Magee dirigiu uma encenação de Krapp's Last Tape com o ator Max Wall, e Beckett mencionou a Magee que as alterações que havia feito com o ator Martin Held em Berlim, em 1969, se encaixavam perfeitamente no estilo do trabalho de seu ator. Apesar disso, Beckett evitou participar da direção da peça, em respeito ao trabalho de Patrick Magee.

Como se viu Beckett não trabalhou com Magee para fazer a sua produção refletir em detalhes a encenação de Beckett em Berlim. O fato de que ele mencionou as mudanças, mas não fez nenhuma tentativa de imposição em relação à direção de Magee sugere que ele manteve sua imagem de Magee como o Krapp original [como ele mais tarde confirmou a Jean Martin], mas também pensava que as inovações obtidas com Held formaram uma parte integral de sua peça. (MCMILLAN; FEHSENFELD, 1988, p. 256, tradução nossa) 
Samuel Beckett realizaria, em 1969, sua primeira encenação de Das letzte Band [A última gravação de Krapp], apresentada no Schiller-Theater, na cidade de Berlim. Originalmente a peça foi encenada na Werkstatt, uma sala de formato pequeno, voltada a encenações experimentais, monólogos, e peças curtas. Foi durante o processo desta encenação que Beckett realizou suas mais importantes e definitivas mudanças em relação ao texto original da peça.

Beckett possuía uma visão extremamente detalhista e meticulosa no que se refere à transposição de suas peças de teatro para o palco, e sabemos que isso não se iniciou com suas encenações de suas próprias peças, mas sim com o processo de acompanhamento das montagens que outros encenadores faziam de seus textos teatrais ${ }^{1}$. Mas a exegese de Beckett em relação à encenação de suas peças aumentaria gradativamente ao longo das décadas de 1950, 1960 e 1970, na medida em que sua experiência prática no teatro se tornava mais extensa, culminando na encenação de Dias felizes no Royal Court Theatre de Londres, em 1979, com a atriz Billie Whitelaw no papel de Winnie.

Apesar do grande envolvimento de Beckett e Whitelaw, a quem ele considerava sua melhor intérprete feminina, os relatos da atriz e de pesquisadores que acompanharam os ensaios de Dias felizes mostram que a relação diretor-atriz, naquele processo de criação, foi extremamente tensa e delicada. Segundo relatos, a tensão entre ambos, gerada pela frustração de Beckett em relação ao fato de que Whitelaw demorava a internalizar mudanças na partitura de atuação durante os ensaios, explodiria em tensões que obrigariam inclusive a uma parada temporária nos ensaios da peça. De acordo com Whitelaw, o desentendimento teria se dado devido a mudanças realizadas por Beckett em relação ao texto original da peça, ocorridas durante os ensaios sem aviso prévio ou tempo para novos estudos, o que segundo ela teria atrapalhado seu processo de criação da personagem, depois de ter passado meses estudando milimetricamente cada detalhe do texto dramatúrgico. James Knowlson menciona que "Beckett modificou o texto depois que Billie Whitelaw já havia aprendido o papel e isto colocou uma grande pressão sobre seu relacionamento, geralmente próximo" (KNOWLSON; KNOWLSON, 2007, p. 172, tradução nossa). Isto demonstra como a exegese do autor-diretor poderia ser problemática durante os ensaios, principalmente se pensarmos

\footnotetext{
${ }^{1}$ Abordamos a trajetória de Samuel Beckett na seara da direção teatral em artigo publicado pela Revista Magma. SANTOS, F. A. S.. Samuel Beckett: de dramaturgo a encenador. Magma (USP), v. 12, pp. 163-180, 2015.
} 
que Whitelaw havia realizado a versão definitiva da peça Footfalls [Passos] três anos antes, em 1976, em parceria com Beckett, recebendo amplos elogios do autor, que escrevera a peça para a atriz.

No Schiller-Theater, o texto de A última gravação de Krapp sofreria mudanças importantes, tanto textuais como relativas ao figurino, aos elementos cênicos e à iluminação. Uma das mais significativas seria a inserção de um cubículo [cubby hole] iluminado e separado do restante do palco por uma pequena cortina, que estaria fechada no início da peça, e que após a movimentação de Krapp em seu interior para a retirada do gravador, do livro de registro e de outros objetos, permaneceria por todo o restante da representação semiaberta, com a iluminação interna vazando para o fundo do palco, quebrando a atmosfera de total escuridão fora da faixa de luz que ilumina a mesa do personagem, conforme é descrita no texto original da peça. Também foram retiradas as duas gavetas que se abriam em direção ao público, no momento das pantomimas com a banana e as fitas virgens. No lugar delas, Beckett adicionou apenas uma gaveta lateral, simplificando dessa forma a movimentação do personagem em cena, que Beckett buscava tornar mais ágil e direta. Também foram alteradas as pantomimas com a banana, inclusive a marca onde Krapp recolocava a banana descascada em seu bolso, com a ponta saindo, em clara alusão sexual. Outra mudança importante no que se refere à teatralidade foi a substituição das "caixas de papelão" (BECKETT, 1999, p. 1) por caixas de estanho para armazenamento das fitas gravadas, o que conferia mais dramaticidade e realismo à cena, devido ao ruído proveniente das mesmas durante a movimentação do personagem. A iluminação, que chegou a se mover em busca do personagem em uma das primeiras versões do texto, passa a se manter fixa, conforme a versão original da peça publicada em 1958, mas é ampliada minimalisticamente pelo espectro de luz que vaza do pequeno cubículo ao fundo do palco. Portanto a iluminação total do palco, segundo o caderno de direção de Beckett, sofreria uma mudança significativa, devido à luz difusa do cubículo semi-aberto no fundo do palco, que vaza para o restante do palco durante praticamente toda a representação, diminuindo dessa forma o contraste rígido entre luz e escuridão proposto por Beckett na rubrica do texto publicado em 1958.

Mas uma das mudanças mais significativas resultantes da encenação no SchillerTheater, em 1969, foi a completa retirada da maquiagem e caracterização clownesca de Krapp, conforme era descrita na rubrica do texto original. Em substituição ao "rosto branco", ao "nariz purpúreo", às "calças pretas curtas demais para ele" e ao "surpreendente par de 
botas brancas e imundas" (BECKETT, 1999, p. 1), Beckett opta por nova caracterização, mantendo as características originais do figurino [detalhes em preto e branco], mas eliminando por completo a maquiagem branca com nariz purpúreo, tipicamente clownesca, as calças curtas [trocadas por calças pretas de comprimento maior, que chegavam a cobrir a parte superior dos sapatos do personagem], e as botas de bico longo [trocadas por um par de sapatos brancos gastos e encardidos], em clara intenção de tornar a representação menos caricatural, e mais próxima do realismo-naturalismo. Beckett manteria tais alterações em todas as outras encenações que realizou da peça, chegando a mencionar que o texto definitivo da peça seria o texto com as alterações da encenação (KNOWLSON, 1992).

Outro dado importante que surge da relação do Beckett encenador com sua própria dramaturgia seria o comentário feito pelo autor a Marcel Mihalovici, quando do trabalho conjunto para a preparação do texto para a ópera Krapp², onde "Beckett reconheceu que as gravações de Krapp eram como um álbum de fotografias, evocando lembranças de momentos centrais do seu passado" (BECKETT apud MCMILLAN; FEHSENFELD, 1988, p. 327, tradução nossa). Isto nos permite refletir acerca da importância dos registros das vozes para Krapp, dentro do contexto de confinamento e total isolamento em que o personagem está mergulhado. Com relação ao aspecto da materialidade realista da cena, predominante em A última gravação de Krapp, evidenciada através da ambientação minimalista e realista da peça pela encenação de Beckett, Ruby Cohn menciona a contraposição entre detalhes realistas e não realistas presentes nas anotações do caderno de direção de Beckett.

Ao contrário do caderno de direção de Fim de partida, o caderno de direção de Krapp não divide a peça em cenas de ensaio. Em vez disso, Beckett lista vinte e sete questões que necessitam de atenção da direção, a partir da metafísica "1. Choix-hasard" até a extremamente física "27. Endgültig Werkstatt". Beckett calcula que Krapp tem gravado por quarenta e cinco anos, uma vez que há nove caixas, cada uma contendo cinco rolos de fita. O caderno de direção designa o gravador como um agente masturbatório, e Beckett instruiu Held a segurar a caixa eroticamente. Sua separação da fala em relação ao movimento, introduzida em Come and Go e Fim de partida, torna-se o fulcro da performance: "Peça portanto composta de duas partes aproximadamente iguais, escuta/imobilidade e não-

\footnotetext{
${ }^{2}$ Krapp, ou, La dernière bande [versão inglesa: The Last Tape; versão alemã: Krapp, oder Das letzte Band] é uma ópera de câmara em um ato, dirigida por Marcel Mihalovici com o libretto feito por Samuel Beckett. O libretto foi baseado na versão original de 1958 de Krapp's Last Tape, e grande parte do texto dramatúrgico foi utilizada em sua confecção. Da mesma forma que a peça, a ópera é um monólogo com apenas o personagem Krapp em cena. A ópera foi encomendada em conjunto pela Radiodiffusion-Télévision Française e pela Städtische Bühnen em Bielefeld, Alemanha. Desde o início, o libretto da ópera foi concebido em três diferentes línguas: em inglês [a partir do texto dramatúrgico original], em francês [para a estreia francesa] e em alemão [para a estreia alemã]. (KNOWLSON, 1992)
} 
escuta/movimento." Para a escuta, Beckett iniciou os ensaios com uma fita provisória de Krapp aos trinta e nove anos de idade, que foi posteriormente substituída. (COHN, 1980, pp. 245-246, tradução nossa)

A questão da relação erótico-afetiva de Krapp com seu gravador fica evidente em alguns momentos da peça, especialmente quando o personagem escuta as passagens da gravação de seu eu de trinta e nove anos, e rememora os momentos envolvendo as mulheres que fizeram parte de sua trajetória. Iniciando sua primeira fala na peça com a procura da "caixa três" e do "rolo cinco" (BECKETT, 1999, p. 3), Krapp se depara com anotações no livro de registro relativas à morte de sua mãe e posteriormente ao encontro com a enfermeira morena. De sua meditação preparatória da primeira cena, Krapp mergulha na audição do desejado rolo cinco, onde se depara imediatamente com a passagem em que menciona a "velha senhora McGlome" (BECKETT, 1999, p. 4). Progressivamente Krapp se depara com registros de seus encontros com mulheres, desde os mais significativos, como o comentário acerca de sua companheira Bianca [única menção de Krapp à vida a dois] (BECKETT, 1999, p. 4), passando pela garota na plataforma da estação de trem, a enfermeira morena, a garota no bote e finalmente Fanny, a prostituta com quem Krapp manteve, ao que parece, um relacionamento de cunho sexual. Krapp também chega a fantasiar com Effie3, heroína do romance Effi Briest, se perguntando em dado momento se "poderia ter sido feliz com ela, no mar Báltico, entre os pinheiros e as dunas" (BECKETT, 1999, p. 9).

As indicações de Beckett presentes nas rubricas relativas às passagens onde Krapp se recorda destas figuras femininas já possuíam leve conotação afetiva, mas em sua encenação no Schiller-Theater Beckett ampliou tais referências, dirigindo o ator Martin Held de forma que este se aproximasse ainda mais do gravador, arqueando seu corpo e aproximando suas mãos do aparelho como se tentasse tocar no corpo das mulheres através do corpo do gravador.

Outra ênfase importante proveniente das modificações resultantes da encenação no Schiller-Theater diz respeito aos momentos em que Krapp escuta as gravações de seu outro eu aos trinta e nove anos. Se nas rubricas do texto original Beckett menciona que Krapp medita ao escutar tais passagens, na direção de sua montagem da peça no Schiller-Theater

\footnotetext{
${ }^{3}$ De acordo com Dougald McMillan e Martha Fehsenfeld, "heroína do romance de Theodore Fontaine, mas também, segundo Patrick Magee, uma conhecida da vida real de Beckett." (MCMILLAN; FEHSENFELD, 1988, p. 249, tradução nossa)
} 
Beckett explorou a visualização minuciosa e altamente concentrada, por parte de Martin Held, de todos os momentos em que Krapp medita parecendo querer resgatar as imagens de sua memória com a máxima precisão possível, chegando a propor ao ator determinados movimentos com a cabeça e com os olhos, no intento de enfatizar a importância desses momentos em relação ao público.

Martin Held concedeu um importante depoimento a Ronald Hayman acerca de sua relação com Samuel Beckett durante os ensaios de Das letzte Band no Schiller-Theater, em 1969. Held inicia sua fala evidenciando os desconfortos gerados por Beckett, como diretor, nos primeiros ensaios da peça.

No início, ele parece ter sentido que deveria me dizer muito do que ele podia se lembrar da primeira produção [no Royal Court Theatre, Londres, 1958] e isto foi, é claro, um começo não tão feliz, especialmente pelo fato de que Beckett não era realmente um diretor. Se ele tivesse sido um diretor, ele teria traduzido o que o ator anterior tinha feito para mim, mas devido ao fato de que ele não era um diretor, ele não poderia fazer isso. (HELD apud KNOWLSON; KNOWLSON, 2007, p. 183, tradução nossa)

O comentário de Held se aproxima, aqui, de muitos mitos acerca do controle rígido de Beckett em suas encenações e de algumas inverdades acerca de seu suposto desconhecimento das particularidades relativas ao trabalho de direção e encenação de teatro. Se tomarmos por base a extensa e meticulosa preparação que Beckett fazia para cada uma de suas encenações no Schiller-Theater berlinense, amplamente documentadas em seus cadernos de direção, percebemos que o olhar do encenador era tão agudo quanto o do dramaturgo. Segundo Ruby Cohn:

Na primeira reunião de Beckett com os atores de uma peça, ele nunca fala sobre a peça, mas mergulha diretamente nela. $O$ trabalho com as cenas começa de uma vez, e Beckett balança a cabeça sobre questões que fogem do desempenho concreto. Por outro lado, nenhum detalhe prático é pequeno demais para a sua atenção. Sentado ou em pé, ele parece pronto para saltar para o palco. No início dos ensaios, ele pede permissão para interromper os atores, sempre concedida. O texto falado deve ser não apenas textualmente perfeito, mas ter a pontuação perfeita; ele interrompe qualquer ator que elidir uma pausa de vírgula. No entanto, ele raramente interrompe os primeiros ensaios gerais, e ele deliberadamente se ausenta de um ensaio tardio ou dois, para que os atores possam sentir-se mais livres em suas descobertas finais. Embora Beckett chegue ao Schiller-Theater com a produção completa no olho de sua mente, ele geralmente faz pequenas alterações durante os ensaios. (COHN, 1980, p. 237, tradução nossa) 
O comentário da professora e pesquisadora Ruby Cohn reforça e amplia o que havíamos mencionado anteriormente neste artigo, no que se refere ao trabalho de Beckett como encenador. Mas retornando a Martin Held e à experiência de colaboração com Samuel Beckett em A última gravação de Krapp, percebemos que segundo os comentários do ator acerca do convívio prático com Beckett em sala de ensaio, o processo de encenação também possibilitou momentos de grande liberdade criativa em meio à rigidez e exegese formais do autor de Esperando Godot.

Havia trechos em que ele me deixava completamente livre até o último dia. Por exemplo, a última fita que eu gravei, ele não disse nada a respeito; eu apenas gravei. Conversávamos às noites com uma garrafa de vinho tinto. Ele ficava lá sentado naquela cadeira e nós de nenhuma forma falávamos exclusivamente sobre a peça. Ele falava muito sobre James Joyce, a quem conhecia bem, e dali voltávamos novamente para a peça. Para mim, uma das melhores coisas de nossa colaboração, e algo que eu sempre gosto de fazer, era que algumas vezes ele dizia "vamos guardar essa situação para os últimos dias de ensaios. Nós ainda não fomos tão longe para que possamos estar completamente certos sobre isso". Esta era uma forma lindamente flexível de trabalhar. Eu acho isso o método ideal de direção. Muitas vezes ele entrava em detalhes, por exemplo, em relação àqueles olhares em direção à parte traseira, como quando Krapp está escutando ou quer ligar o gravador, e ele salta e se vira lentamente. Ele ensaiava essas coisas meticulosamente. Elas eram mais do que apenas direções de palco. Beckett fala bem alemão e nos demos bem desde o início, de tal forma que eu sabia exatamente o que ele queria dizer, por exemplo, quando disse que a Morte, a quem Krapp tem procurado inconscientemente, está de pé arás dele ou que, quando ele escuta, ele desliga-se e afunda em sonhos; Krapp é devorado por sonhos. Mas isso ocorre sem sentimentalismo; não há resignação nele. É o término, o fim. Não há nada mais a dizer sobre isso. [...] (HELD apud KNOWLSON; KNOWLSON, 2007, p. 185, tradução nossa)

É possível notarmos um paradoxo entre a paródia de controle em suas peças, presente nas relações de poder atuantes em alguns de seus personagens, tais como Pozzo, Hamm, Winnie e Krapp, e o controle da direção exercida por ele em suas produções. Dentre tantos paradoxos explicitados através de imagens presentes em suas peças, este paradoxo entre o olhar do Beckett dramaturgo e o olhar do Beckett diretor chama atenção. Se o controle era alvo de ironia em sua dramaturgia, parodiado e criticado através de falas de personagens e situações dramáticas, no trabalho do Beckett diretor ele se torna uma estratégia no sentido de assegurar o padrão estético e formal de seu teatro, potencializado através da materialidade de suas encenações. 
Nas encenações dirigidas por Beckett, além do minimalismo e da exegese cênica citados, devemos mencionar também a questão da associação de Beckett entre sua prática teatral e elementos provenientes da música. Beckett elaborava verdadeiras partituras para seus personagens, e cuidava em suas encenações para que fossem executadas à risca, com seus atores trabalhando como músicos conduzidos por um maestro em um concerto. Tudo era extremamente rígido e preciso, e como na música, a liberdade do intérprete residia no preenchimento dos espaços deixados pela direção, no colorido interpretativo relativo aos detalhes da partitura de ações físicas. Devemos nos lembrar que Beckett possuía formação musical, tocava piano, e era casado com uma exímia pianista, sua esposa Suzanne Beckett. Segundo Anna McMullan, "o controle da direção por Beckett poderia garantir que esta estrutura rítmica milimétrica seria realizada nas performances [de suas peças]" (MCMULLAN, 1994, p. 198, tradução nossa).

Diversos críticos associam a questão rítmica e os padrões presentes na dramaturgia de Beckett com a música. De acordo com Stanley Gontarski, Beckett "move o drama para mais próximo do espírito da música e para longe de seu nível mimético e referencial" (GONTARSKI apud MCMULLAN, 1994, p. 198, tradução nossa). As repetições e circularidades presentes em suas peças também apontam para estratégias de composição musical, e o ritmo e andamento propostos em sua dramaturgia [e reforçados em suas encenações] tornam o teatro de Beckett quase que um jogo entre a estética teatral e a coreografia partiturada de sons e movimentos.

A direção de Beckett de Das letzte Band no Schiller-Theater Werkstatt, em 1969, com Martin Held como Krapp, se aproximou do ballet em seu uso meticuloso de gestos e movimentos para retratar os temas da peça. Em determinado momento Beckett até mesmo se advertiu a "evitar o excesso de estilização". Para esta produção ele fez as alterações textuais e de ações de palco que completam a edição original de Faber. Esta versão teve sua origem no caderno de direção com 71 folhas [...] que Beckett preparou antes de chegar em Berlim, mas também deve muito aos detalhes desenvolvidos durante os ensaios. O caderno de direção de Beckett reflete o processo: páginas 1-81, [escrito em francês enquanto ele ainda estava em Paris ou Ussy] contém seu plano preliminar para a representação que ele visualizou - frequentemente com questões e alternativas. Páginas 83-91 abaixo do título "Endgültig - Werkstatt 5-10-69" [Final - Werkstatt] são um resumo detalhado em inglês e alemão das ações desenvolvidas nos ensaios. (MCMILLAN; FEHSENFELD, 1988, p. 258, tradução nossa)

Além do caderno de direção contendo as anotações feitas por Beckett, resultantes, conforme pudemos observar, tanto dos estudos preparatórios prévios ao processo de ensaios 
como do próprio processo de ensaios da peça, outro registro dos detalhes do processo de produção da primeira versão alemã de Beckett de $A$ última gravação de Krapp existe e chegou a ser publicado4. Ele foi desenvolvido a partir das anotações decorrentes dos ensaios feitas pelo ator que interpretou Krapp na encenação apresentada no Schiller-Theater, Martin Held. O registro, mais detalhado e contendo diversas fotos da produção, funciona quase como um Modellbuch brechtiano5.

O texto publicado em 1970 do Suhrkamp Regiebuch der Berliner Inszenierung [...], com base no roteiro de atuação anotado de Held e autorizado por Beckett, contém uma versão geralmente mais completa e em alguns pontos diferente em relação ao caderno de direção contendo as alterações feitas para esta produção. Ele também possui 113 fotografias que mostram a postura e os gestos de Held. Ele é, de longe, o texto publicado mais definitivo de Krapp. Estas três versões raramente estão em conflito, mas muitas vezes se complementam. [...] A versão de Das letzte Band finalmente apresentada era uma peça mais bem integrada e mais poderosa do que a presente tanto no original em inglês como no esboço preliminar feito antes dos ensaios. O desenvolvimento desta versão, através dos estágios do caderno de direção até o texto publicado no Regiebuch, é um dos melhores exemplos de Beckett como diretor utilizando a experiência prática dos ensaios para realizar mudanças como autor. (MCMILLAN; FEHSENFELD, 1988, p. 258, tradução nossa)

Em relação à encenação realizada no Schiller-Theater em 1969, existe ainda mais um registro do trabalho de Beckett decorrente de seu acompanhamento relativo a um registro televisivo da montagem com Martin Held. O documento, intitulado "Sugestões para um Krapp na T.V." ${ }^{6}$, fornecido por Beckett para a gravação em vídeo feita pela emissora Westdeutsche

\footnotetext{
${ }^{4}$ Tanto este Suhrkamp Regiebuch der Berliner Inszenierung, publicado em 1970, como o Theatrical notebooks of Samuel Beckett vol. III: Krapp's Last Tape, publicado em 1992, encontram-se esgotados em suas respectivas editoras. Segundo depoimento de Stanley Gontarski a este pesquisador durante sua visita a São Paulo em 2014, isto se deve à disputa entre visões de críticos e editores acerca dos textos revisados por Beckett durante as suas encenações de suas peças, contendo as diversas alterações realizadas sobre os textos originais das peças. Para alguns críticos [como Gontarski], os textos revisados correspondem à versão final e definitiva das peças de Beckett, o que era corroborado pela própria visão do autor. Para outros, as modificações propostas a partir dos ensaios e representações das peças empobreciam com suas modificações a perfeição das peças originais.

${ }^{5}$ Segundo Patrice Pavis, "a representação "modelo" do Modellbuch brechtiano nada tem de um modelo exemplar a ser imitado: é um modelo reduzido, uma maquete da encenação, um dossiê composto de fotografias, de indicações de atuação, de análises dramatúrgicas e de caracterização das personagens. Ela fixa as etapas da elaboração do espetáculo, registra as dificuldades do texto e propõe um quadro geral para a interpretação. Para Brecht, que começou no Berliner Ensemble esses modelos de representação, estes deveriam servir de base para futuros encenadores, sem, todavia, serem usados tal e qual nas encenações posteriores. Dentro do mesmo espírito do Modellbuch, os volumes de Les Voies de La Création Théâtrale [CNRS] reconstituem espetáculos propondo sua análise dramatúrgica e fornecendo uma rica documentação.". (PAVIS, 1999, 246)

${ }^{6} \mathrm{O}$ referido documento foi publicado por Dougald McMillan e Martha Fehsenfeld em seu excelente estudo acerca do trabalho de Beckett como diretor de suas peças de teatro. (MCMILLAN; FEHSENFELD, 1988, pp. 287288)
} 
Rundfunk da performance de Martin Held, mostra um aprofundamento dos efeitos da produção do Schiller-Theater. Conforme comenta Clas Zilliacus, a "hierarquia dos "níveis de intencionalidade, ou valores de escuta" de Krapp encontra paralelos óbvios no Regiebuch: as câmeras são feitas para reforçar partículas ou segmentos de ação que já foram enfatizados na performance" (ZILLIACUS apud MCMILLAN; FEHSENFELD, 1988, p. 287, tradução nossa). Dessa forma, o princípio central do trabalho das câmeras é elucidativo. Através da captação das imagens produzidas no palco pelas câmeras, a peça deve ser clarificada.

Samuel Beckett voltaria a trabalhar em transposições de $A$ última gravação de Krapp para os palcos, como encenador e como supervisor de montagens de outros diretores. Beckett colaborou com o diretor Roger Blin em sua produção de La dernière bande no Théâtre Récamier em 1960, e dez anos mais tarde, repetiria seu papel de colaborador-supervisor com o diretor Jean-Louis Barrault no mesmo teatro. Jean Martin, que havia trabalhado como assistente de direção na montagem de Blin em 1960, interpretou o papel de Krapp na encenação de Barrault, em 1970. Segundo Martin, diferentemente da parceria com Blin, onde Beckett atuara apenas como supervisor, em grande parte pelo respeito que tinha pelo trabalho do diretor, na encenação de Barrault para Krapp Beckett tomou as rédeas de boa parte da direção. De acordo com o relato de Jean Martin, muitas das alterações feitas por Beckett na dramaturgia da peça durante a produção do Schiller-Theater, em 1969, já estavam sendo pensadas pelo autor para as encenações do Théâtre Récamier. Ator da produção francesa de 1970, Martin posteriormente escreveu depoimento por carta a Dougald McMillan e Martha Fehsenfeld acerca do trabalho de Beckett durante o processo de montagem da peça.

Sam queria que a peça fosse representada sem sentimentalismo. Todo o nosso trabalho consistiu em fazer de Krapp um velho homem que se lembra de seu passado, mas sem o distanciamento, apenas com um pouco de nojo. Esta peça é de certa forma muito autobiográfica, o que explica a recusa de Sam em torná-la sentimental, enquanto mantinha sua dimensão como o que se poderia chamar de quase trágica... Eu me lembro particularmente da morte da mãe, com o episódio do pequeno cão e a bola. Sam insistiu que eu interpretasse a cena sem a adição de qualquer sentimentalismo. A dificuldade era evitar ser frio e neutro, pois Sam não queria isso também. $\mathrm{E}$ eu tinha que ter certeza de não cair em lembranças emocionais; deveria seria antes algum tipo de repugnância. Outra veio do fato de que a peça tinha sido escrita em inglês e depois traduzida para o francês, mas tinha sido pensada originalmente com palavras e respirações em inglês, que trazem um sentido diferente em francês. E Sam foi muito insistente para que encontrássemos em francês o tipo de ritmo que se encontra no inglês. Desde a primeira produção da peça Sam sempre indicou 
que em alguns momentos muito precisos Krapp viraria um pouco para olhar para trás na escuridão. Isso sempre foi feito e sempre foi cuidadosamente encenado assim como as três viagens para ir buscar as fitas, o livro de registro e o gravador. Há detalhes como as bananas para os quais Sam sempre quis que prestássemos bastante atenção. E ele queria que Krapp se curvasse cada vez mais em direção ao gravador na medida em que a ação da peça transcorria, de modo a terminar completamente deitado sobre ele, quase dando a impressão de que Krapp age com o gravador da mesma forma como havia agido com a mulher no barco. (MARTIN apud MCMILLAN; FEHSENFELD, 1988, p. 257, tradução nossa)

Se Beckett vislumbrava as alterações necessárias ao texto dramatúrgico de $A$ última gravação de Krapp desde o processo de montagem da peça em 1960 com Roger Blin na direção, foi somente na montagem do Schiller-Theater que as mudanças foram definitivamente incorporadas ao texto de 1958. Esse texto dramatúrgico modificado se tornaria o modelo para todas as outras produções da peça posteriores à sua encenação de 1969, fato que se manifesta na encenação parisiense de 1970, cujo relato de Jean Martin nos possibilita percebermos as similitudes com o relato do ator Martin Held, o Krapp da versão realizada no Schiller-Theater apenas um ano antes.

Beckett ainda realizaria outras encenações importantes de $A$ última gravação de Krapp, mas nenhuma com o impacto que a montagem do Schiller-Theater representou em relação à dramaturgia. Em 1975, Beckett dirigiria uma encenação de La dernière bande com o ator Pierre Chabert [com quem havia trabalhado em sua primeira direção profissional, em 1966, da peça L'Hypothèse, de Robert Pinget], no Petit Théâtre d'Orsay. A encenação apresentava uma novidade em relação à atuação, com Beckett dirigindo um ator de 35 anos de idade no papel de Krapp, diferentemente do trabalho realizado na Alemanha em 1969, com Martin Held aos 61 anos, portanto mais próximo da idade do Krapp que vemos em cena, no aniversário de seus 69 anos. Embora as alterações textuais da encenação berlinense tenham sido mantidas, transpostas para as particularidades da cultura francesa [com elementos como a boina negra adotada por Chabert para cobrir parte dos cabelos de Krapp], Beckett realizaria mais algumas modificações significativas em relação à estrutura da peça.

Para esta produção de Krapp, Beckett discutiu os princípios estruturais da peça mais extensamente do que o habitual. A descrição de Chabert de seu trabalho em conjunto é de certa forma uma indicação ainda mais completa do que o caderno de direção do Schiller, no que se refere à coordenação intrincada de todos os elementos da peça. (MCMILLAN; FEHSENFELD, 1988, p. 288, tradução nossa) 
A descrição detalhada de todos os elementos trabalhados por Beckett e Chabert durante a encenação francesa de Krapp em 1975 nos proporciona um vislumbre da profundidade e agudeza do olhar do Beckett encenador, ampliando o detalhamento de ações físicas, intenções, atmosfera, expressões faciais, entre outros elementos. As anotações relativas aos ensaios mencionadas por Chabert7 apontam para uma série de elementos desenvolvidos durante a encenação, tais como o ritual de escuta e gravação, o trabalho com o texto e a voz, as duas vozes (gravações e Krapp ao vivo em cena), o trabalho sobre o texto (entendimento e alterações), as interrupções de falas ou exclamações, a exclamação das palavras, as interrogações e lembranças, a ação, o corpo, o espaço, a audição, a máscara e as expressões faciais, as reações à escuta, os sonhos, a relação emocional com o gravador, o espaço duplo, o corpo, o silêncio e os ruídos, a musicalidade do corpo e dos objetos, e por fim a questão do ritmo e da repetição.

Segundo James Knowlson (1997, p. 617), Beckett acabara de retornar de Berlim no dia 9 de março de 1975, completamente exausto, mas satisfeito com a repercussão de sua encenação de Warten auf Godot [Esperando Godot] no Schiller-Theater, e com apenas um dia de descanso, mergulhou em uma maratona de ensaios de aproximadamente um mês, envolvendo sua encenação de Pas moi [Not l], com Madeleine Renaud e La dernière bande [A última gravação de Krapp].

No entanto, cansado como estava, ele se dedicou ao máximo, encontrando uma série de novas e fascinantes ideias de produção para Pierre Chabert em $A$ última gravação de Krapp - a sombra de Krapp sendo vista bebendo na parede de seu covil e a lâmpada acima de sua cabeça que começou a balançar quando Chabert, originalmente por acidente, a atingiu com a cabeça enquanto ele se levantava - tudo mantido por ele. [...] Ele escreveu "eu gosto do Krapp de Chabert"8. (KNOWLSON, 1997, p. 617, tradução nossa)

A iluminação da encenação de 1969 no Schiller-Theater berlinense permanece a mesma, com o detalhe do reforço do espectro de luz advindo do cubículo semi-aberto, mas Beckett assume como marcação de cena o movimento em que Krapp bate a cabeça na lâmpada, criando certa instabilidade e movimentação da faixa de luz durante a representação, mais uma vez conferindo um maior realismo à cena e redimensionando um dos elementos centrais da peça, o contraste entre luz e escuridão.

\footnotetext{
${ }^{7}$ Cf. McMillan; Fehsenfeld, 1988, pp. 288-296.

${ }^{8}$ Carta de Samuel Beckett a Mary Hutchinson, 15 de abril de 1975, tradução nossa. (KNOWLSON, 1997, p. 818)
} 
Em seu longo e detalhado artigo acerca do processo da encenação dirigida por Beckett em 1975, Pierre Chabert nos fornece uma quantidade de informações e detalhes acerca do processo de criação no palco mais extensa do que os registros de Beckett de seu caderno de direção da encenação alemã de 1969 . E o fato do artigo ter sido escrito pelo ator que representou Krapp, ao invés do dramaturgo-encenador, nos fornecem um vislumbre diverso em relação à prática de encenação de Beckett, apontando elementos de forma minuciosa, possibilitando ao leitor um mergulho na atmosfera do processo de encenação da peça em Paris. No início do artigo, Chabert faz uma observação acerca do trabalho de Beckett como encenador:

[...] Beckett é diretor muito antes de realmente assumir os ensaios ou trabalhar com os atores. Neste aspecto ele representa um exemplo único - talvez até um limite - na história do teatro. A verdadeira encenação da peça está sempre escrita em seus textos. Eles são caracterizados por uma forma teatral de escrita na qual o discurso nunca está dissociado do espaço ou da linguagem concreta do palco. O discurso nunca é concebido como algo separado do gesto, do movimento, do lugar, do posicionamento físico e da postura corporal. (KNOWLSON, 1980, pp. 85-86, tradução nossa)

No ano de 1977, Beckett dirigiria sua segunda produção berlinense de $A$ última gravação de Krapp, mas desta vez em língua inglesa, com o ator Rick Cluchey, integrante do San Quentin Drama Workshop, apresentada na Akademie der Künste em setembro de 1977, como parte do Berliner Festwochen. Esta produção de A última gravação de Krapp acontecera a partir de um convite de Rick Cluchey, o ator que havia encenado Esperando Godot na Penitenciária de San Quentin, enquanto cumpria sua pena, no ano de 1961. Mais uma vez, Beckett manteria as alterações relativas ao texto da peça desenvolvidas durante a encenação de 1969, mas acrescentando mais algumas alterações decorrentes do processo de ensaios da peça (MCMILLAN; FEHSENFELD, 1988, p. 296).

Ao longo das diversas experiências descritas neste artigo envolvendo Beckett e a encenação de $A$ última gravação de Krapp, a peça sofreu alterações provenientes do processo prático no campo da encenação que conferiram à sua dramaturgia um detalhamento minimalista impressionante, ampliaram e aprofundaram questões, e propuseram soluções cênicas para problemas advindos do texto original, mostrando que a visão de Beckett acerca de seu teatro foi verticalmente aprimorada neste verdadeiro diálogo com sua alteridade artística, ou seja, no diálogo do Beckett encenador com o Beckett dramaturgo. 
REFERÊNCIAS BIBLIOGRÁFICAS

ADORNO, Theodor W. Notes on Beckett. In: Journal of Beckett Studies. 2010, Vol.19, n.2, pp. 157-178.

ANDRADE, Fábio de Souza. Samuel Beckett: o silêncio possível. São Paulo: Ateliê Editorial, 2001.

ASMUS, Walter D. Practical aspects of theatre, radio and television - rehearsal notes for the german premiere of Beckett's That time and Footfalls at the Schiller-Theater Werkstatt, Berlin (directed by Beckett). In: Journal of Beckett Studies. Trad. Helen Watanabe. Summer 1977, n.2. 
pp. 82-95.

BECKETT, Samuel. The complete dramatic works. London: Faber and Faber, 1990. . A última gravação de Krapp. Trad. Felipe de Souza. São Paulo: 1999.

BERRETINI, Celia. A linguagem de Beckett. São Paulo: Perspectiva, 1977.

BERRETINI, Celia. Samuel Beckett: escritor plural. São Paulo: Perspectiva, 2004.

BIRKENHAUER, Klaus. Samuel Beckett. Trad. Federico Latorre. Madrid: Alianza Editorial, 1976.

BRATER, Enoch. Fragment and Beckett's form in 'That time' and 'Footfalls'. In: Journal of Beckett Studies. Summer 1977, n.2. pp. 70-81.

CHABERT, Pierre (ed.). Revue d'Esthétique: Hors série 1990. Paris: Jean-Michel Place, 1990.

COHN, Ruby. Back to Beckett. Princeton: Princeton University Press, 1974.

. Just play: Beckett's theater. Princeton: Princeton University Press, 1980.

CONNOR, Steven. Presence and repetition in Beckett's theatre. In: Samuel Beckett: repetition, theory and text. Oxford: Blackwell, 1988, pp. 129-154.

ESSLIN, Martin. Twentieth century interpretations of Samuel Beckett: a collection of critical essays. New Jersey: Prentice Hall, 1965.

. O Teatro do absurdo. Trad. Barbara Heliodora. Rio de Janeiro: Zahar, 1968.

FARIAS JÚNIOR, Manoel Moacir Rocha. Beckett: silêncios. São Paulo: Annablume, 2011.

FLETCHER, John; SPURLING, John. Beckett: a study of his plays, London: Eyre Methuen, 1972.

GONTARSKI, S. E. The intent of undoing in Samuel Beckett's dramatic texts. Bloomington: Indiana University Press, 1985.

GONTARSKI, S. E. (Org.). On Beckett: essays and criticism. New York: Grove Press, 1986.

GONTARSKI, S. E. (ed.). The theatrical notebooks of Samuel Beckett Vol. 4: the shorter plays. London and New York: Faber and Faber and Grove Press, 1999.

GONTARSKI, S. E. Revisando a si mesmo: o espetáculo como texto no teatro de Samuel Beckett. In: Sala Preta - revista do PPG em Artes Cênicas ECA-USP. Trad. Robson Corrêa de Camargo e Adriana Fernandes. São Paulo: ECA-USP, 2008, n. 8, pp. 261-280.

GUSSOV, Mel. Conversations with and about Beckett. New York: Grove Press, 1996.

HARTEL, Gaby; VOLKER, Klaus; IRMER, Thomas. The reception of Beckett's theatre and television pieces in West and East Germany. In: NIXON, Mark; FELDMAN, Matthew (ed.). The international reception of Samuel Beckett. New York: Continuum, 2009, pp. 75-96. 
JANVIER, Ludovic. Beckett. Trad. Léo Schlafman. Rio de Janeiro: José Olympio Editora, 1988. KALB, Jonathan. Beckett in performance. Cambridge: Cambridge University Press, 1991.

KNOWLSON, James. Krapp's Last Tape: the evolution of a play, 1958-1975. In: Journal of Beckett Studies. Winter 1976, n.1, s-p.

KNOWLSON, James. Practical aspects of theatre, radio and television - extracts from an unscripted interwiew with Billie Whitelaw by James Knowlson. In: Journal of Beckett Studies. Summer 1978, n.3, pp. 85-90.

KNOWLSON, James (ed.). Theater Workbook 1: Samuel Beckett, Krapp's Last Tape. London: Brutus Books, 1980.

KNOWLSON, James; MCMILLAN, Dougald (eds.). The theatrical notebooks of Samuel Beckett vol.1: Waiting for Godot. New York: Grove Press, 1994.

KNOWLSON, James (ed.). The theatrical notebooks of Samuel Beckett vol.3: Krapp's Last Tape. London: Faber and Faber, 1992.

KNOWLSON, James. Damned to fame: the life of Samuel Beckett. London: Bloomsburry Publishing, 1997.

KNOWLSON, James; KNOWLSON, Elizabeth (eds.). Beckett remembering, remembering Beckett. London: Bloomsbury, 2007.

LAWLEY, Paul. Stages of identity: from Krapp's last tape to Play. In: PILLING, John (ed.). The Cambridge companion to Beckett. Cambridge: Cambridge University Press, 1994.

MCMILLAN, Dougald; FEHSENFELD, Martha. Beckett in the theatre: the author as a practical playwright and director. London: John Calder, 1988.

MCMULLAN, Anna. Beckett as director: the art of mastering failure. In: PILLING, John (ed.). The Cambridge companion to Beckett. Cambridge: Cambridge University Press, 1994.

MORRISON, Kristin. Canters and chronicles: the use of narrative in the plays of Samuel Beckett and Harold Pinter. Chicago and London: The University of Chicago Press, 1986.

OPPENHEIM, Lois. Directing Beckett. Ann Arbor: The University of Michigan Press, 1997.

PAVIS, Patrice. Diccionario del teatro. Trad. Fernando de Toro. Barcelona: Paidós, 1983.

. Dicionário de teatro. Trad. Eudynir Fraga, J. Guinsburg, Maria Lúcia Pereira, Nanci Fernandes, Rachel Araújo de Baptista Fuser. São Paulo: Perspectiva, 1999.

POUNTNEY, Rosemary. Theatre of shadows: Samuel Beckett's drama 1956-1976. Gerrards Cross: Colin Smythe, 1988. 
RAMOS, Luiz Fernando. O parto de Godot e outras encenações imaginárias. São Paulo: HUCITEC, 1999.

ROBINSON, Michael. The long sonata of the dead: a study of Samuel Beckett. London: Rupter Hart-Davis, 1970.

SARRAZAC, Jean-Pierre (org.). Léxico do drama moderno e contemporâneo. São Paulo: Cosac Naify, 2012.

VASCONCELLOS, Cláudia Maria de. Teatro inferno: Samuel Beckett. São Paulo: Terracota, 2012.

VOIGTS-VIRCHOW, Eckart. Shades of negativity and self-reflexivity: the reception of Beckett in german literary studies. In: NIXON, Mark; FELDMAN, Matthew (ed.). The international reception of Samuel Beckett. New York: Continuum, 2009, pp. 97-107.

i i Doutorando em Teoria Literária e Literatura Comparada (DTLLC-FFLCH-USP). 